\title{
Genotypic and Phenotypic Variation among Pepper Accessions Resistant to Phytophthora capsici
}

\author{
Cecilia McGregor ${ }^{1}$ and Vickie Waters \\ University of Georgia, College of Agricultural and Environmental Sciences, \\ Horticulture Department, 1111 Miller Plant Sciences, Athens, GA 30602
}

\begin{abstract}
Savithri Nambeesan
Plant Biology, University of Georgia, Franklin College of Arts and Sciences, Athens, GA 30602
\end{abstract}

\begin{abstract}
Dan MacLean, Byron L. Candole, and Patrick Conner
University of Georgia-Tifton Campus, College of Agricultural and Environmental Sciences, Horticulture Department, 4604 Research Way, Tifton, GA 31793
\end{abstract}

Additional index words. Capsicum annuum, pungency, fruit size, SSR, capsaicinoids

\begin{abstract}
Developing high levels of resistance to Phytophthora blight (Phytophthora capsici Leonian) of pepper (Capsicum annuum L.) is a goal of many pepper breeding programs. Genetic diversity and plant characteristics were evaluated on 21 pepper accessions previously identified as having high levels of Phytophthora root rot resistance. Accessions were evaluated for plant height, fruit size and shape, pericarp thickness, and pungency. Accessions varied widely from very unadapted material to those with more obvious breeding potential. Genetic diversity among the accessions was estimated using 22 simple sequence repeat (SSR) loci. Phytophthora capsici resistant accessions were identified that were not closely related to previously described sources of resistance. This information will allow breeders and researchers to further identify and incorporate novel sources of resistance to $P$. capsici into breeding programs. Accessions PI 201237 and PI 640532 appear to have the most potential for introgressing $P$. capcisi resistance into bell pepper.
\end{abstract}

The oomycete Phytophthora capsici Leonian causes root and fruit rot, stem blight, and foliar blight in pepper (Capsicum annuum L.) (Leonian, 1922) causing global yield losses (Babadoost, 2004). Currently the disease is managed through the use of resistant cultivars, fungicides, and cultural practices such as crop rotation (Louws et al., 2008; Ristaino and Johnston, 1999). However, its wide host range (Erwin and Ribeiro, 1996) spanning at least 14 families including economically important Cucurbitaceae, Solanaceae, and Leguminosae crops and many weeds makes control through crop rotation challenging. The additional development of resistance to fungicides (CaféFilho and Ristaino, 2008; Hausbeck and Lamour, 2004) have led to more concerted efforts to develop $P$. capsici resistant pepper cultivars.

Resistance to $P$. capsici has been reported (Alcantra and Bosland, 1994; Bartual et al., 1994; Bosland and Lindsey, 1991; Gil-Ortega et al., 1991; Guerrero-Moreno and Laborde, 1980) and is best described for the landrace CM-334 in which different genes control resistance to root rot, foliar blight, and stem

Received for publication 11 Apr. 2011. Accepted for publication 27 June 2011.

This research was funded by USDA CREES (NIFA Award No.: 2008-34571-19413).

${ }^{1}$ To whom reprint requests should be addressed; e-mailcmcgre1@uga.edu. blight (Sy et al., 2005; Walker and Bosland, 1999). Recently, Candole et al. (2010) described several new sources of resistance to P. capsici. Despite these sources of resistance, currently no bell or chile pepper cultivar is consistently resistant to all disease symptoms under field conditions (Oelke et al., 2003; Sy et al., 2008). Breeding cultivars resistant to $P$. capsici is not only complicated by the different disease symptoms, but also by the diversity of the pathogen itself. At least 20 $P$. capsici races have been identified using host differentials (Oelke et al., 2003; Sy et al., 2008) and host resistance to different races is often controlled by different genes (Monroy-Barbosa and Bosland, 2008). Breeders are therefore always on the lookout for new sources of resistance in the hope that it will provide resistance to additional $P$. capsici races and/or disease symptoms.

For breeders to make informed decisions about which resistant accession(s) to use in their breeding programs, it would be useful to have information related to important horticultural traits and the genetic diversity among these accessions. To shorten the time required to develop resistant cultivars, breeders would prefer to use resistant accessions that have similar horticultural characteristics to the cultivar being developed. Breeders are also interested in incorporating different resistance genes into cultivars (gene pyramiding) to obtain broader, more durable resistance (Stuthman et al., 2007). Without knowledge about the particular gene/alleles involved in resistance, breeders can incorporate resistance from different genetic backgrounds to increase the probability of broader resistance.

The traits important to pepper breeding will depend on the type of pepper the breeder is interested in developing. The specific goals in breeding bell pepper and chile pepper could vary substantially (Bosland and Votava, 2000). Fruit shape and size are important considerations to most breeders, although the specific goals differ, e.g., large blocky fruit for bell peppers and long narrow fruit for 'Cayenne'. Pericarp thickness is another important trait with thick pericarp desirable for bell pepper but thin pericarp for peppers that are commonly dried (e.g., paprika types). Plant height may also have a significant influence with compact morphologies required for bell pepper, whereas larger plants are preferred for chile pepper (Crosby, 2008). Consumers expect a specific pungency level from certain pepper types, for example Jalapeño is expected to be less pungent than Cayenne. Moreover, bell peppers are non-pungent, whereas the degree of pungency in chile peppers varies greatly (Bosland and Votava, 2000; Crosby, 2008). The chemicals responsible for pungency are collectively called capsaicinoids, which can be measured using high-performance liquid chromatography (HPLC; Collins et al., 1995). Capsaicin and dihydrocapsaicin are responsible for $80 \%$ to $95 \%$ of total capsaicinoids and are therefore good indicators of fruit pungency (Bennett and Kirby, 1968; Cavett et al., 2004)

Knowledge of the genetic diversity among $P$. capsici resistant accessions and commercial cultivars would benefit plant breeders. The $P$. capsici resistant cultivar CM-334 has been extensively used in breeding programs (Monroy-Barbosa and Bosland, 2008; Ortega et al., 1991). Breeders wanting to introduce new $P$. capsici resistance genes into their programs probably want to use a source that is not genetically closely related to CM-334. The use of SSR markers to determine genetic variation and uniformity within and between accessions are well established in many crops, including pepper (Hanáček et al., 2009; Kwon et al., 2005; Portis et al., 2007; Tam et al., 2005; Tommasini et al., 2003). Knowledge of genetic diversity among resistant accessions would help breeders to choose accessions based on this information.

The aim of this study is to determine phenotypic variation of horticulturally important traits and genetic variation among the $P$. capsici resistant accessions identified by Candole et al. (2010).

\section{Materials and Methods}

Plant material. Seeds from 21 accession lines previously reported to be resistant to P. capsici (Candole et al., 2010) were planted in seedling trays at the University of Georgia South Milledge greenhouses in Athens, GA, on 5 May 2009. The word "line" is used as described in Candole et al. (2010) to indicate selfed seed from an individual plant of 
a specific accession. We will refer to all of these PIs as accessions, regardless of improvement status. The commercial hybrid cultivars Camelot (Rupp Seeds, Wauseon, $\mathrm{OH}$ ) and Aristotle (Rupp Seeds), the open-pollinated 'Early Jalapeno' (Lake Valley Seed Inc., Boulder, $\mathrm{CO}$ ), and the P. capsici resistant control 'Criollo de Morelos 334' (CM-334; supplied by P. Bosland) were included in this study. Two weeks after germination, four plants of each accession or cultivar were transplanted into 6.1-L Azalea pots (ITLM Horticultural Products Inc., Brantford, Ontario, Canada) filled with Fafard 3B mix (Conrad Fafard, Inc., Agawam, MA) and $11 \mathrm{~g}$ Osmocote (14N4.2P-11.6K; Scotts Miracle-Gro, Marysville, $\mathrm{OH})$ per pot. As a result of poor germination of CM-334, only two plants were available for transplant and further analysis. Temperature in the greenhouse varied from 24 to $27^{\circ} \mathrm{C}$ and 27 to $29^{\circ} \mathrm{C}$ (night/day). Plants were watered twice a day and fertilized once a week with water-soluble fertilizer $(20 \mathrm{~N}-8.7 \mathrm{P}-16.6 \mathrm{~K})$ to provide $200 \mathrm{ppm}$ nitrogen starting at 2 weeks after transplanting. Plants were selfed by hand as required to ensure sufficient fruit production. Samples were collected from three randomly chosen plants from each accession/ cultivar for further analysis.

Horticultural characteristics. Average fruit weight was calculated for the mature green fruit that was used for pungency determination. Length (FL) and width (FW) of mature green fruit from each plant were measured (total of seven fruits per accession/cultivar) before processing for pungency determination. Fruit shape was calculated as the ratio of average length to average width (FS $=\mathrm{FL} /$ FW; Thabuis et al., 2004). Between 133 and $171 \mathrm{~d}$ after transplanting (DAT), data were taken on the fruit position (pendent or erect) and the color of mature fruits was recorded. Plant height (staked) was taken at the end of the experiment at 175 DAT.

Pungency. At least three mature green fruit were harvested from each of three plants per line between 56 and 170 DAT depending on the accession. The number of fruit harvested was determined by the size of the fruit with more fruits harvested from lines produc- ing small fruits to ensure at least $1 \mathrm{~g}$ of dried material (Collins et al., 1995) was available for pungency determination. Fruits were sliced and dried between 2 and $5 \mathrm{~d}$ at $58{ }^{\circ} \mathrm{C}$ and then ground to a fine powder without removing seed using a basic analytical mill (Model A11; IKA Works, Inc. Wilmington, NC). Ground samples were stored in static free plastic bags at $-20{ }^{\circ} \mathrm{C}$ until further processing.

High-performance liquid chromatographydiode array detector sample preparation and analysis. For extraction of capsaicinoids, $\approx 1 \mathrm{~g}$ of dried tissue was placed in $10 \mathrm{~mL}$ of acetonitrile and incubated at $80^{\circ} \mathrm{C}$ for $4 \mathrm{~h}$. A small aliquot $(1.2 \mathrm{~mL})$ of the supernatant was then centrifuged at $16,000 \mathrm{~g}$ for $15 \mathrm{~min}$ at $8^{\circ} \mathrm{C}$ using a Beckman-Coulter Allegra 25R centrifuge equipped with a TA-15-1.5 rotor. The sample was then transferred into a $1.8-\mathrm{mL}$ amber HPLC vial fitted with a polytetrafluoroethylene screw-on cap. Capsaicinoids were separated and identified using an Agilent 1200 series HPLC (Foster City, CA) system equipped with an inline continuous vacuum solvent degasser, binary pump, temperature-controlled

Table 1. Simple sequence repeat primers used in this study.

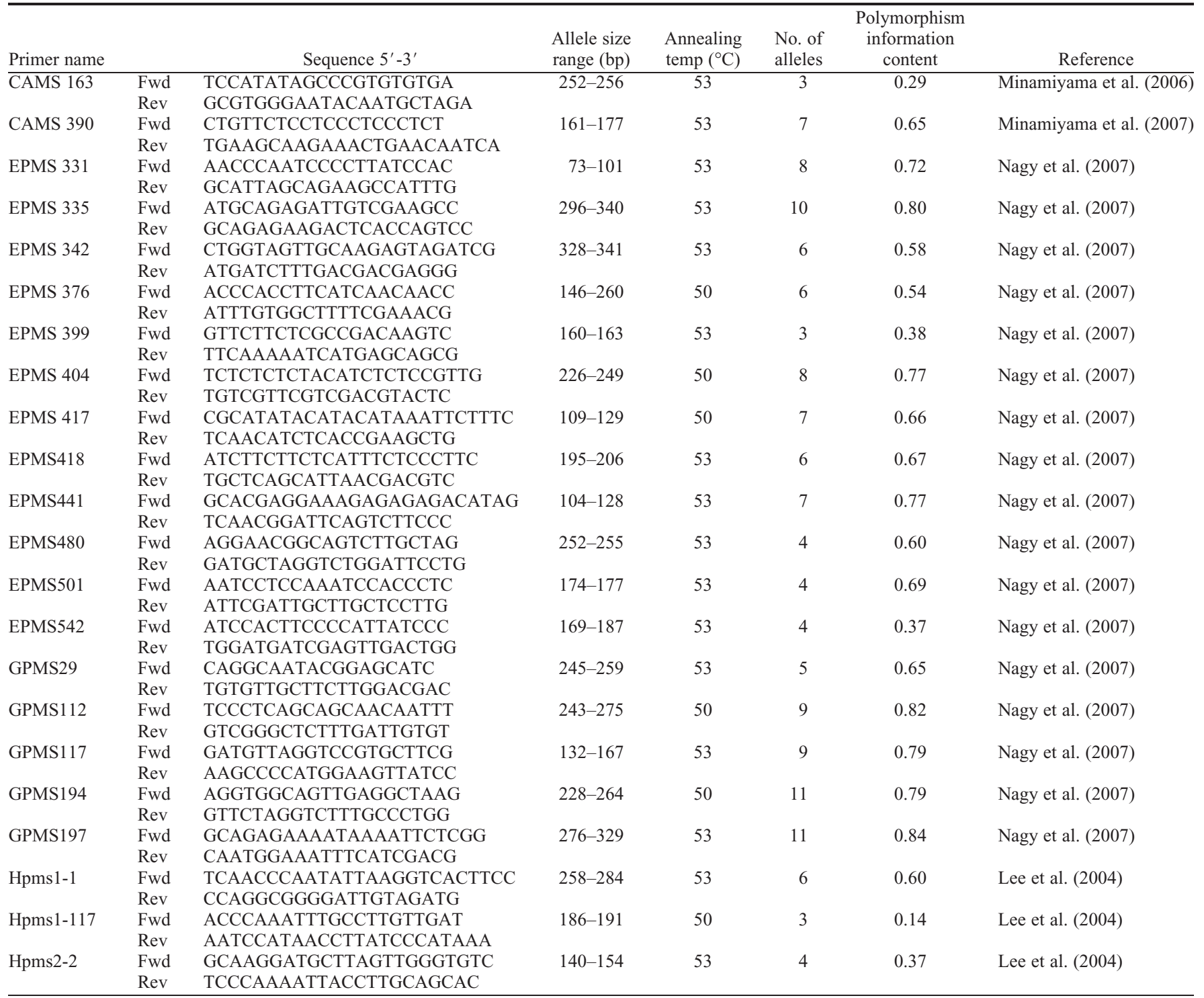


autosampler and column compartments, and a photodiode-array detector (PDA), all controlled by Chemstation (revision B.03.01) software package. Solvents used were A: water and $\mathrm{B}$ : acetonitrile run isocractically at $60 \% \mathrm{~B}$ at a flow rate of $1.000 \mathrm{~mL} \cdot \mathrm{min}^{-1}$. The autosampler compartment was maintained at $4{ }^{\circ} \mathrm{C}$. The volume of injection for both samples and standards was $10 \mu \mathrm{L}$. The capsaicinoid compounds were retained using an Agilent Eclipse XDB-C18 column $(150 \mathrm{~mm} \times 4.6 \mathrm{~mm} \times 5 \mu \mathrm{m}$; Foster City, CA) protected by a guard column $(12.5 \mathrm{~mm} \times 4.6 \mathrm{~mm} \times 5 \mu \mathrm{m})$ of the same phase, all held at $30{ }^{\circ} \mathrm{C}$ within the column compartment. Eluted compounds were detected using the PDA equipped with a semimicro flow cell with a full spectral scan set from 190 to $350 \mathrm{~nm}$ ( $2 \mathrm{~nm}$ steps) and monitored at $280 \mathrm{~nm}$ for the detection of capsaicinoids (bandwidth $4 \mathrm{~nm}$ ). Capsaicinoids and dihydrocapsaicinoids were identified based on similarity of retention time and spectral characteristics with authentic standards. Scoville heat units (SHUs; Scoville, 1912) were calculated by multiplying the sum of ppm capsaicin and dihydrocapsaicin by 15 (Bosland and Votava, 2000).

Genetic diversity and linked markers. Three leaf disks were collected from three plants of each accession/cultivar using the lid of a microfuge tube as a punch. Samples were immediately frozen in liquid nitrogen and stored at $-80{ }^{\circ} \mathrm{C}$ until processing. Samples were ground with 5-mm stainless steel beads (Qiagen, Inc., Valencia, CA) using the TissueLyser system (Qiagen, Inc.). DNA was extracted from ground samples using a GenElute Plant Genome DNA miniprep kit (Sigma-Aldrich Inc., St. Louis, $\mathrm{MO})$. DNA concentration was measured using a NanoDrop (Model ND-8000; Thermo Fisher Scientific Inc., Waltham, MA) and diluted if necessary.

Twenty-two previously published SSR primer pairs (Table 1) were used in this study. The reaction contained between 10 and $100 \mathrm{ng}$ template DNA, $0.4 \mu \mathrm{M}$ of a fluorescently labeled (6FAM, HEX, or 6TAM) forward and unlabeled reverse primer, $400 \mu \mathrm{M}$ of each dNTP, 0.6 U Taq DNA polymerase (NEB; New England Biolabs, Ipswich, MA), and $1 \times$ standard Taq buffer (NEB) in $20 \mu \mathrm{L}$ total reaction volume. Polymerase chain reaction (PCR) products were amplified in 96-well plates on a MyCycler (Bio-Rad, Hercules, CA) using 1-min initial denaturation followed by one cycle of $25 \mathrm{~s}$ at $95^{\circ} \mathrm{C}, 25 \mathrm{~s}$ at $56^{\circ} \mathrm{C}$, and $30 \mathrm{~s}$ at $72{ }^{\circ} \mathrm{C}$. In every following cycle, the denaturing temperature was reduced by $1{ }^{\circ} \mathrm{C}$ until it reached $53{ }^{\circ} \mathrm{C}$. The subsequent 36 cycles consisted of $20 \mathrm{~s}$ at $95^{\circ} \mathrm{C}, 20 \mathrm{~s}$ at $53^{\circ} \mathrm{C}$, and $30 \mathrm{~s}$ at $72{ }^{\circ} \mathrm{C}$. For some primers, a base annealing temperature of $50{ }^{\circ} \mathrm{C}$ was used instead of $53{ }^{\circ} \mathrm{C}$ (Table 1), and in such cases, the initial stepdown was carried out for six cycles followed by 33 cycles at the base annealing temperature. The amplification was followed by a final extension step of $15 \mathrm{~min}$ at $72{ }^{\circ} \mathrm{C}$.

Amplifications were carried out separately for each primer pair; products were diluted either $2.5 \times$ or $5 \times$ depending on observed band intensity on an agarose gel. Three primer pairs (one for each fluorescent label) were pooled

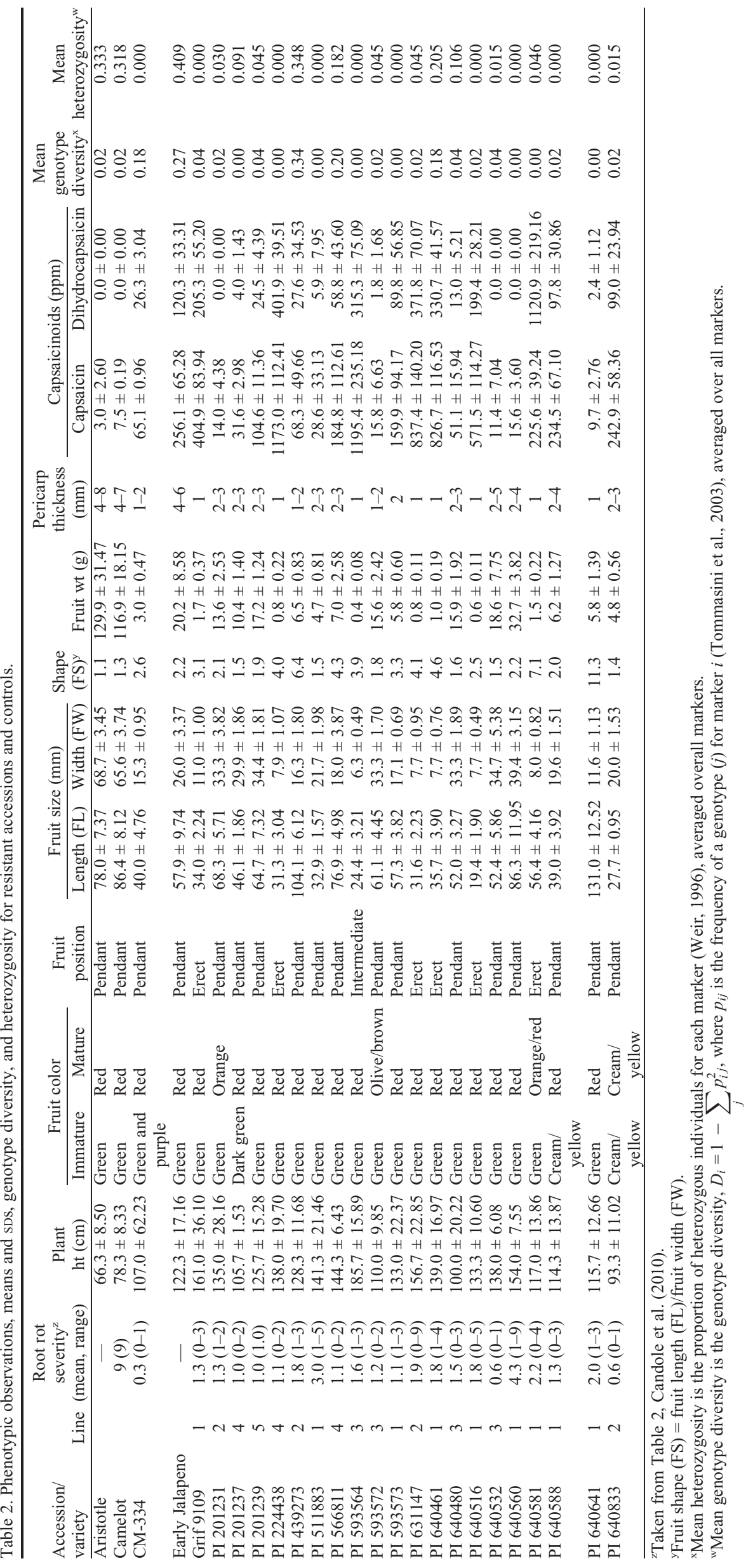


together. The diluted products were combined with a GeneScan-500 ROX internal-lane size standard (ABI; Applied Biosystems by Life Technologies Corporation, Carlsbad, CA) and $50 \%$ formamide before analysis on the Applied Biosystems 3730xl 96-capillary DNA Analyzer (ABI) at the Georgia Genomics Facility. GeneMapper software Version 4.0 (ABI) was used for allele scoring and size estimation.

PowerMarker Version 3.25 (Liu and Muse, 2005) was used to calculate frequency-based distances (Nei et al., 1983) and draw a tree based on the unweighted pair group method with arithmetic mean (Sneath and Sokal, 1973) that was visualized in Tree View (Page, 1996). Heterozygosity (Weir, 1996) and polymorphism information content (PIC; Botstein et al., 1980) were also calculated using PowerMarker, whereas genotype diversity was calculated as described by Tommasini et al. (2003).

The DNA used for SSR analysis was also used for amplification of the D04 sequence characterized amplified region (SCAR) marker reported to be linked to the Phyto 5.2 resistance locus of CM-334 (Quirin et al., 2005). The reaction contained between 10 and $100 \mathrm{ng}$ template DNA, $0.4 \mu \mathrm{M}$ of each primer (Quirin et al., 2005), $400 \mu \mathrm{M}$ of each dNTP, 0.6 U Taq (NEB; New England Biolabs), and $1 \times$ standard Taq buffer (NEB) in $20 \mu \mathrm{L}$ total volume. PCR products were amplified using $90 \mathrm{~s}$ initial denaturation followed by 35 cycles of $15 \mathrm{~s}$ at $95^{\circ} \mathrm{C}, 20 \mathrm{~s}$ at $55^{\circ} \mathrm{C}$, and $30 \mathrm{~s}$ at $72^{\circ} \mathrm{C}$ followed by a final single elongation step of $15 \mathrm{~min}$ at $72{ }^{\circ} \mathrm{C}$. In addition, all samples were amplified with the ITS-A and ITS-B primers described by Blattner (1999) using identical conditions as described previously to ensure that fragments could be amplified from all samples (data not shown).

All amplified fragments were separated using $1.5 \%$ agarose gel electrophoresis and Benchtop PCR markers (Promega Corporation, Madison, WI) were included to estimate fragment size.

\section{Results and Discussion}

The resistant accessions show a large amount of both phenotypic and genetic diversity among accessions (Table 2; Figs. 1 and 2).

Horticultural characteristics. The accessions generally have a tall growth habit compared with commercial bell pepper cultivars, similar to 'Early Jalapeno', but some accessions (e.g., PI 593564) were even taller (Table 2). Compact size is usually desired in commercial bell pepper cultivars. PI 201239 and PI 640833 were two of the most compact accessions investigated.

Fruits were generally small and elongated with a thin pericarp (Table 2). PI 640560 had the largest fruit and, along with PI 640532, and PI 640588 also had relatively thick pericarp. Both erect and pendant pedicel positions were observed. Except for PI 201231, PI 593572, and PI 640581, which had orange, olive/ brown, and orange/red mature fruit color, respectively, all accessions had red mature fruit. Depending on the breeding objectives, breeders

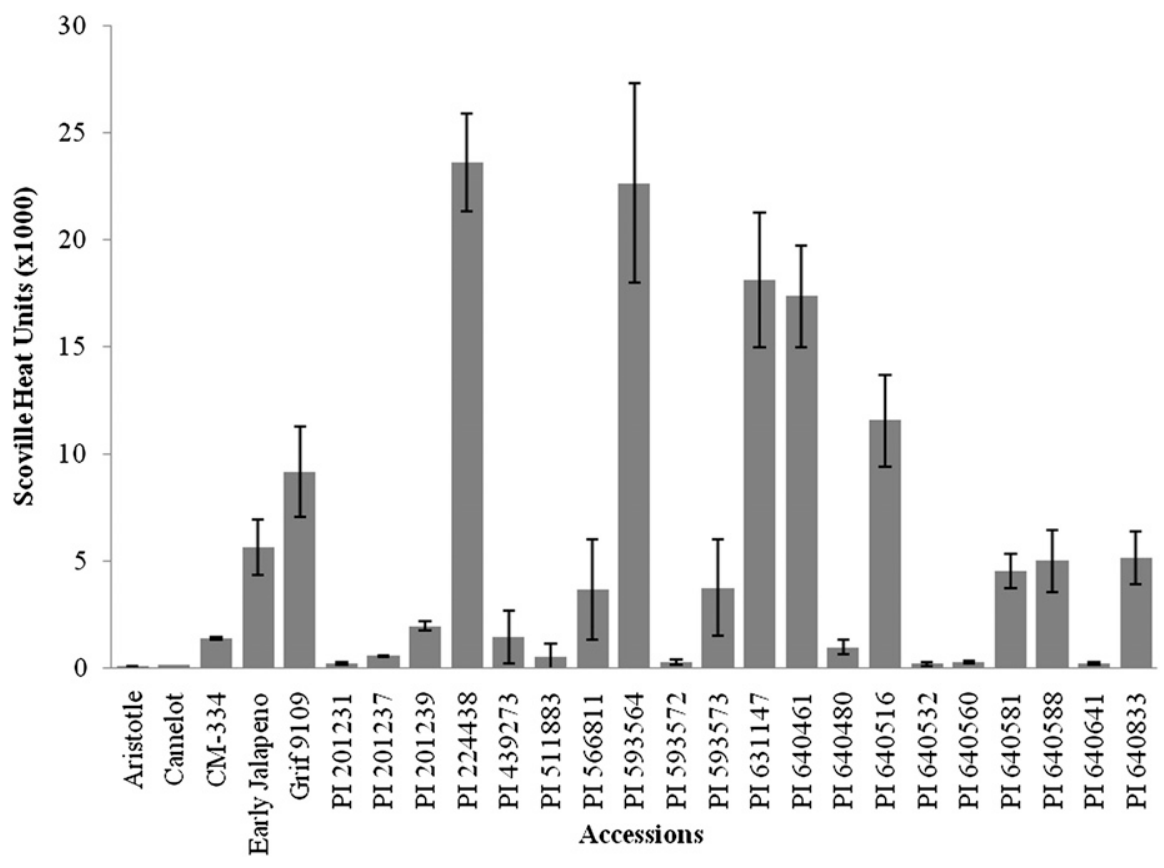

Fig. 1. Pungency [Scoville heat units (SHU)] of resistant accessions and controls. SHU was calculated as $15 \times(\mathrm{ppm}$ capsaicin + ppm dihydrocapsaicin $)$. Bars indicate SD.

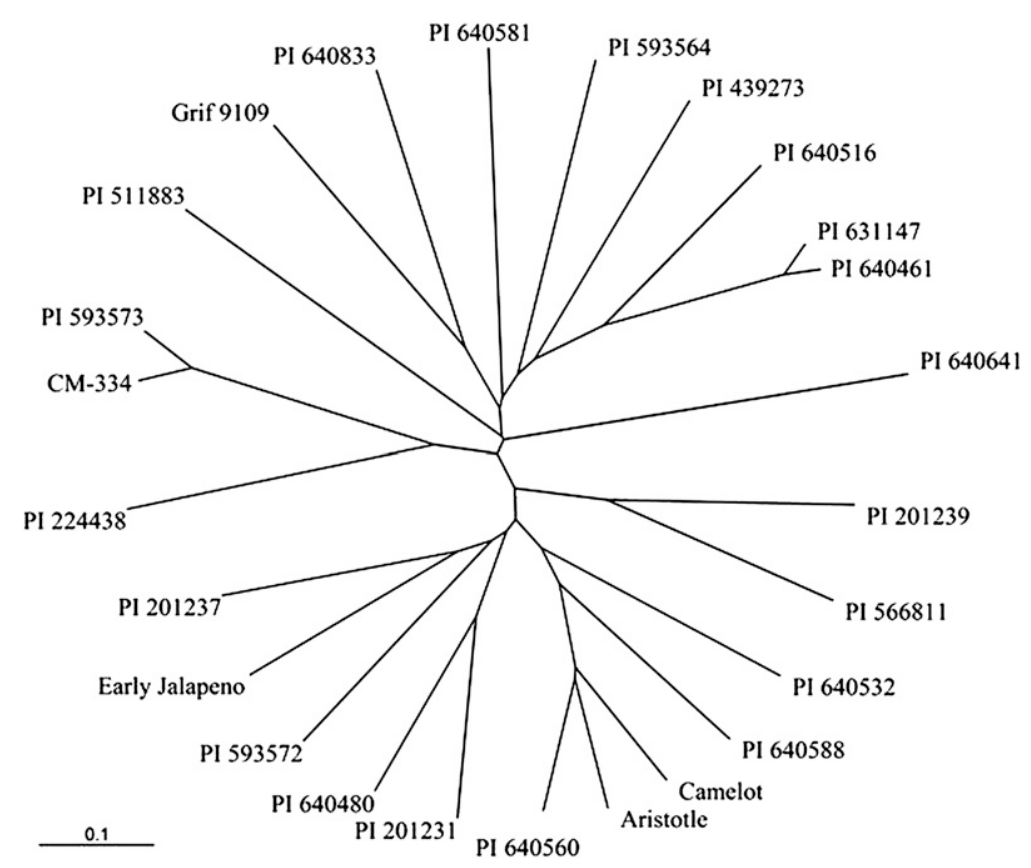

Fig. 2. Unrooted tree displaying the genetic relationships among the resistant accessions and controls.

should choose resistant accessions that have horticultural characteristics suitable to their requirements.

The phenotypic data were collected in a single greenhouse experiment and it is expected that absolute values for traits like plant height, fruit size, and fruit weight will be different under field conditions. However, it is likely that general trends will hold true, for example that PI 201239, PI 593572, and PI 640480 will have heavier fruit than PI 511883, PI 593573, and PI 640833 and that PI 640641 and PI 640581 will have more elongated fruit than PI 201237 and PI 640532.
Pungency. The levels of capsaicin and dihydrocapsaicin varied widely among accessions (Table 2). The pungency (SHU) of the different accessions ranged from trace amounts in PI 640532 and PI 640641 to $\approx 23,000$ SHUs in PI 224438 and PI 593564 (Fig. 1). Because capsaicinoids are produced only in the placenta, larger fruit with thick pericarp tend to have lower capsaicinoid levels as a result of the dilution effect of the inclusion of pericarp and seeds (Ben-Chaim et al., 2006). Indeed, PI 640532 and PI 640560 and other accessions with relatively large fruit and thick pericarp (Table 2) had low pungency (Fig. 1). 


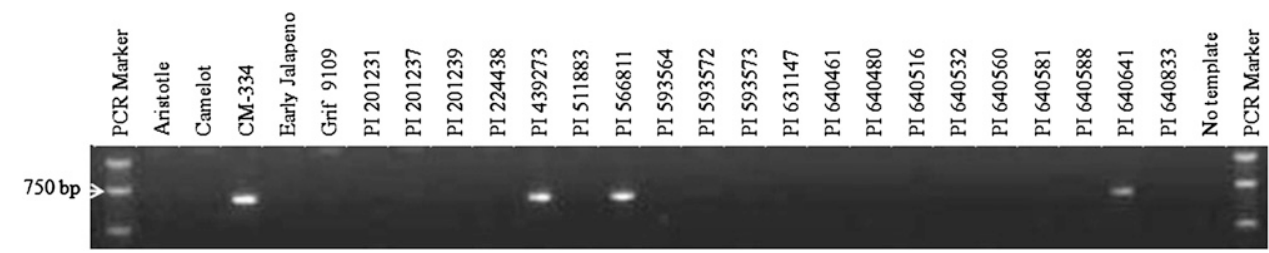

Fig. 3. Electrophoresis showing amplification products using D04 sequence characterized amplified region primers. In CM-334, this marker has been shown to be linked to the Phyto 5.2 resistance locus (Quirin et al., 2005).

The presence or absence of pungency is controlled by a single gene, Pun 1, coding for a putative acyltransferase (Deshpande, 1935; Stewart et al., 2005; Webber, 1911). The loss of function allele at this locus leads to absence of pungency in the homozygous recessive state (Stewart et al., 2005). When capsaicinoids are present, the amount of capsaicinoids is a quantitative trait controlled by several loci (BenChaim et al., 2006; Blum et al., 2003; Zewdie and Bosland, 2000a). Breeders should select resistant accessions with pungency levels that would best fit their ultimate breeding goals. However, it should be noted that pungency is influenced by the environment (Zewdie and Bosland, 2000b) and therefore values may be different under field conditions.

Genetic diversity and linked markers. Broadly the accessions can be classified into two main clades (Fig. 2). Two accessions, PI 511883 and PI 640641, are genetically different from other accessions and each other. PI 511883 is a chile pepper that was purchased from a market in the Rio Balsas region of Mexico, and PI 640641 is a Cayenne cultivar from Indonesia.

PI 593573, one of the most resistant accessions under field conditions (Candole et al., 2010), is genetically (Fig. 2) and phenotypically (Table 2) very similar to the known resistant CM-334 and this increases the likelihood that these two accessions have the same resistance genes/alleles. If breeders want to increase the probability of introducing several resistance genes/alleles into their breeding material, it would be prudent to introduce resistance from accessions that are not closely related.

In an effort to further elucidate potential new sources of resistance, markers previously described to be linked to resistance loci in CM-334 were investigated. Two SSR primer pairs, CAMS163 and CAMS390, previously reported to be linked to two separate loci associated with $P$. capsici resistance in CM334 (Minamiyama et al., 2007) were included in this study. CAMS163 was not very informative (PIC $=0.29$; Table 1 ) and all accessions except for 'Early Jalapeno', PI 201237, PI 201239, and PI 593572 shared at least one allele at this locus with CM-334. CAMS390 was more polymorphic $(\mathrm{PIC}=0.65$; Table 1$)$ with only PI 593573, PI 439273, and PI 566811 sharing alleles with CM-334 at this locus (data not shown). Quirin et al. (2005) developed a SCAR marker that is linked to the Phyto5.2 resistance locus of CM-334, the same locus linked to CAMS163 (Minamiyama et al., 2007). An amplified fragment for this SCAR marker was detected for PI 439273, PI 566811, and PI 640641 (Fig. 3). Interestingly, no amplification product was observed in PI 593573, the resistant accession closely related to CM334. The presence of a marker allele associated with a resistance locus in a particular accession/population does not necessarily imply the same association in different accessions. To determine whether D04 SCAR is associated with the Phyto 5.2 resistance locus in other accessions, linkage has to be shown in segregating populations. However, until such information becomes available, breeders who want to increase the probability of introducing several resistance genes/alleles into their breeding material should take genetic diversity among accessions (Fig. 2) into account.

Genotype diversity within accessions is a measure of uniformity - how similar individual plants within an accession are to each other (Tommasini et al., 2003). A value of 0 indicates no variation within accessions (all individuals have identical genotypes), whereas a value of 1 indicates that all individuals have different genotypes. PI 439273 had the highest genotype diversity, whereas several accessions show no genotype diversity (Table 2). For accessions that show high genotype diversity, breeders have to take into consideration that these lines are likely to show higher phenotypic variation within lines. There did not seem to be a direct association between genotype diversity scores and the variation of root rot severity reported for these lines by Candole et al. (2010). For example, PI 439273, PI 566811, and PI 640461 had the highest levels of genotype diversity and resistance ranges of 1 to 3,0 to 2 , and 1 to 4 , respectively. In comparison, PI 631147, PI 640516, and PI 640560 had very low levels of genotypic diversity but resistance ranges of 1 to 9,0 to 5 , and 1 to 9 , respectively. This is probably the result of a combination of the inherent variation typical of resistance screens and the small number of plants per accession used in the current study. The genotypic and phenotypic variation within each accession cannot be fully captured using only three plants, leading to an underestimation of variation within accessions.

Although $C$. annuum are generally considered to be self-pollinating, cross-pollination does occur (Pickersgill, 1997). In self-pollinating crops, low levels of heterozygosity would be expected. The majority of accessions show low levels of heterozygosity, with the exception of PI 439273, PI 566811, and PI 640461 (Table 2). Most of the accessions that show high genotype diversity also show high heterozygosity, indicating that outcrossing took place in these accessions. The cultivars Aristotle and
Camelot show low genotype diversity and high heterozygosity as would be expected of $F_{1}$ hybrids from inbred parents.

The information provided by this study will help breeders choose the most appropriate resistant accession(s) to incorporate into their program to achieve their ultimate breeding goals. Two particularly interesting accessions are PI 201237 and PI 640532. These accessions have relatively large fruit, thick pericarps, and high and uniform levels of root rot resistance (Candole et al., 2010). These accessions can potentially be useful for introgressing $P$. capcisi resistance into bell pepper.

\section{Literature Cited}

Alcantra, T.P. and P.W. Bosland. 1994. An inexpensive disease screening technique for foliar blight of chile pepper seedlings. HortScience 29:1182-1183.

Babadoost, M. 2004. Phytophthora blight: A serious threat to cucurbit industries. APSnet Features. Online. doi: 10.1094/APSnetFeature-2004-0404.

Bartual, R., A. Lacasa, J.I. Marsal, and J.C. Tello. 1994. Epistasis in the resistance of pepper to Phytophthora stem blight (Phytophthora capsici L.) and its significance in the prediction of double cross performance. Euphytica 72:149-152.

Ben-Chaim, A., Y. Borovsky, M. Falise, M. Mazourek, B.C. Kang, I. Paran, and M. Jahn. 2006. QTL analysis for capsaicinoid content in Capsicum. Theor. Appl. Genet. 113:1481-1490.

Bennett, D.J. and G.W. Kirby. 1968. Constitution and biosynthesis of capsaicin. J. Chem. Soc. 4:442-446.

Blattner, F.R. 1999. Direct amplification of the entire ITS region from poorly preserved plant material using recombinant PCR. Biotechniques 27:1180-1186.

Blum, E., M. Mazourek, M. O'Connell, J. Curry, T. Thorup, K. Liu, M. Jahn, and I. Paran. 2003. Molecular mapping of capsaicinoid biosynthesis genes and QTL analysis for capsaicinoid content in Capsicum. Theor. Appl. Genet. 108:79-86.

Bosland, P.W. and D.L. Lindsey. 1991. A seedling screen for Phytophthora root rot of pepper, Capsicum annuum. Plant Dis. 75:1048-1050.

Bosland, P.W. and E.J. Votava. 2000. Peppers: Vegetable and spice capsicums. CABI Publishing, Wallingford, UK.

Botstein, D., R.L. White, M. Skolnick, and R.W Davis. 1980. Construction of a genetic linkage map in man using restriction fragment length polymorphisms. Amer. J. Hum. Genet. 32:314-331.

Café-Filho, A.C. and J.B. Ristaino. 2008. Fitness of isolates of Phytophthora capsici resistant to mefenoxam from squash and pepper fields in North Carolina. Plant Dis. 92:1439-1443.

Candole, B.L., P.J. Conner, and P. Ji. 2010. Screening Capsicum annuum accessions for resistance to six isolates of Phytophthora capsici. HortScience 45:254-259.

Cavett, V., E.M. Waninger, and J.J. Krutak. 2004. Visualization and LC/MS analysis of colorless pepper sprays. J. Forens. Sci. 49:1-8. 
Collins, M.D., L.M. Wasmund, and P.W. Bosland. 1995. Improved method for quantifying capsaicinoids in Capsicum using high-performance liquid chromatography. HortScience 30:137139.

Crosby, K.M. 2008. Pepper, p. 221-248. In: Prohens, J. and F. Nuez (eds.). Vegetables II. Springer, New York, NY.

Deshpande, R.B. 1935. Studies in Indian chillies: 4. Inheritance of pungency in Capsicum annuum L. Indian J. Agr. Sci. 5:513-516.

Erwin, D. and O. Ribeiro. 1996. Phytophthora diseases worldwide. American Phytopathological Society, St. Paul, MN.

Gil-Ortega, R., C.P. Espanol, and J.C. Zueco. 1991. Genetics of resistance to Phytophthora capsici in pepper line 'SCM-334'. Plant Breed. 107:50-55.

Guerrero-Moreno, A. and J.A. Laborde. 1980. Current status of pepper breeding for resistance to Phythophthora capsici in Mexico, p. 52-56. Synopses of the IVth meeting of the Capsicum Working Group of Eucarpia, I.V.T. Wageningen, The Netherlands.

Hanáček, P., T. Vyhnánek, M. Rohrer, J. Cieslarová, and H. Stavělíková. 2009. DNA polymorphism in genetic resources of red pepper using microsatellite markers. Horticultural Science (Prague) $36: 127-132$.

Hausbeck, M. and K. Lamour. 2004. Phytophthora capsici on vegetable crops: Research progress and management challenges. Plant Dis. 88:12921303.

Kwon, Y.S., J.M. Lee, G.B. Yi, S.I. Yi, K.M. Kim, E.H. Soh, K.M. Bae, E.K. Park, I.H. Song, and B.D. Kim. 2005. Use of SSR markers to complement tests of distinctiveness, uniformity, and stability (DUS) of pepper (Capsicum annuum L.) varieties. Mol. Cells 19:428-435.

Lee, J.M., S.H. Nahm, Y.M. Kim, and B.D. Kim. 2004. Characterization and molecular genetic mapping of microsatellite loci in pepper. Theor. Appl. Genet. 108:619-627.

Leonian, L.H. 1922. Stem and fruit blight of peppers caused by Phytophthora capsici. Phytopathology 12:401-408.

Liu, K. and S.V. Muse. 2005. PowerMarker: An integrated analysis environment for genetic marker analysis. Bioinformatics 21:21282129.

Louws, F.J., G.J. Holmes, and K.L. Ivors. 2008. Pepper-Phytophthora blight. North Carolina Cooperative Extension Service Factsheet.
Minamiyama, Y., M. Tsuro, and M. Hirai. 2006. An SSR-based linkage map of Capsicum annuum. Mol. Breed. 18:157-169.

Minamiyama, Y., M. Tsuro, T. Kubo, and M. Hirai. 2007. QTL analysis for resistance to Phytophthora capsici in pepper using a high density SSR-based map. Breed. Sci. 57:129-134.

Monroy-Barbosa, A. and P.W. Bosland. 2008. Genetic analysis of Phytophthora root rot racespecific resistance in chile pepper. J. Amer. Soc. Hort. Sci. 133:825-829.

Nagy, I., A. Stágel, Z. Sasvári, M. Röder, and M. Ganal. 2007. Development, characterization, and transferability to other Solanaceae of microsatellite markers in pepper (Capsicum annuит L.). Genome 50:668-688.

Nei, M., F. Tajima, and Y. Tateno. 1983. Accuracy of estimated phylogenetic trees from molecular data. J. Mol. Evol. 19:153-170.

Oelke, L.M., P.W. Bosland, and R. Steiner. 2003. Differentiation of race specific resistance to Phytophthora root rot and foliar blight in Capsicum annuum. J. Amer. Soc. Hort. Sci. 128:213-218.

Ortega, R.G., C.P. Español, and J.C. Zueco. 1991. Genetics of resistance to Phytophthora capsici in the pepper line 'SCM-334'. Plant Breed. 107:50-55.

Page, R.D.M. 1996. Tree View: An application to display phylogenetic trees on personal computers. Computer applications in the biosciences. CABIOS 12:357-358.

Pickersgill, B. 1997. Genetic resources and breeding of Capsicum spp. Euphytica 96:129-133.

Portis, E., I. Nagy, Z. Sasvári, A. Stágel, L. Barchi, and S. Lanteri. 2007. The design of Capsicum spp. SSR assays via analysis of in silico DNA sequence, and their potential utility for genetic mapping. Plant Sci. 172:640-648.

Quirin, E.A., E.A. Ogundiwin, J.P. Prince, M. Mazourek, M.O. Briggs, T.S. Chlanda, K.T. Kim, M. Falise, B.C. Kang, and M.M. Jahn. 2005. Development of sequence characterized amplified region (SCAR) primers for the detection of Phyto.5.2, a major QTL for resistance to Phytophthora capsici Leon. in pepper. Theor. Appl. Genet. 110:605-612.

Ristaino, J. and S. Johnston. 1999. Ecologically based approaches to management of Phytophthora blight of bell pepper. Plant Dis. 83: 1080-1089.

Scoville, W.L. 1912. Note on Capsicum. J. Amer. Pharm. Assoc. 1:453.
Sneath, P.H.A. and R.R. Sokal. 1973. Numerical taxonomy. W. H. Freeman, San Francisco, CA. Stewart C., Jr., B. Kang, M. Mazourek, K. Liu, S.L. Moore, I. Paran, and M.M. Jahn. 2005. The Pun1 gene for pungency in pepper encodes a putative acyltransferase. Plant J. 42:675-688.

Stuthman, D.D., K.J. Leonard, J. MillerGarvin, and L.S. Donald. 2007. Breeding crops for durable resistance to disease. Adv. Agron. 95:319-367.

Sy, O., P.W. Bosland, and R. Steiner. 2005. Inheritance of Phytophthora stem blight resistance as compared to Phytophthora root rot and Phytophthora foliar blight resistance in Capsicum annuum L. J. Amer. Soc. Hort. Sci. 130:75-78.

Sy, O., R. Steiner, and P.W. Bosland. 2008. Recombinant inbred line differential identifies racespecific resistance to Phytophthora root rot in Capsicum annuum. Phytopathology 98:867-870.

Tam, S.M., C. Mhiri, A. Vogelaar, M. Kerkveld, S.R. Pearce, and M.-A. Grandbastien. 2005. Comparative analyses of genetic diversities within tomato and pepper collections detected by retrotransposon-based SSAP, AFLP and SSR. Theor. Appl. Genet. 110:819-831.

Thabuis, A., A. Palloix, B. Servin, A.M. Daubèze, P. Signoret, F. Hospital, and V. Lefebvre. 2004. Marker-assisted introgression of 4 Phytophthora capsici resistance QTL alleles into a bell pepper line: Validation of additive and epistatic effects. Mol. Breed. 14:9-20.

Tommasini, L., J. Batley, G.M. Arnold, R.J. Cooke, P. Donini, D. Lee, J.R. Law, C. Lowe, C. Moule, M. Trick, and K.J. Edwards. 2003. The development of multiplex simple sequence repeat (SSR) markers to complement distinctness, uniformity and stability testing of rape (Brassica napus L.) varieties. Theor. Appl. Genet. 106:1091-1101.

Walker, S.J. and P.W. Bosland. 1999. Inheritance of Phytophthora root rot and foliar blight resistance in pepper. J. Amer. Soc. Hort. Sci. 124:14-18.

Webber, H. 1911. Preliminary notes on pepper hybrids. Amer. Breeders Assoc. Annu. Report 7:188-199.

Weir, B.S. 1996. Genetic data analysis II. Sinauer Associates, Inc., Sunderland, MA.

Zewdie, Y. and P.W. Bosland. 2000a. Capsaicinoid inheritance in an interspecic hybridization of Capsicum annuum $\times$ C. chinense. J. Amer. Soc. Hort. Sci. 125:448-453.

Zewdie, Y. and P.W. Bosland. 2000b. Evaluation of genotype, environment, and genotype-byenvironment interaction for capsaicinoids in Capsicum annuum L. Euphytica 111:185-190. 